\title{
Potential impact of application to the Z0011 trial on the omission of axillary lymph node dissection in women undergoing sentinel node biopsy: a retrospective cohort study
}

Julia Yoriko Shinzato

Universidade Estadual de Campinas

Katia Piton Serra ( $\square$ katiapserra@gmail.com )

Faculdade Sao Leopoldo Mandic https://orcid.org/0000-0003-4117-670X

Caroline Eugeni

Universidade Estadual de Campinas

Cesar Cabello

Universidade Estadual de Campinas

Cassio Cardoso Filho

Universidade Estadual de Campinas

Luiz Carlos Zeferino

Universidade Estadual de Campinas

Research article

Keywords: breast cancer, ACOSOG Z0011, sentinel lymph node, axillary lymph node dissection

Posted Date: August 23rd, 2019

DOI: https://doi.org/10.21203/rs.2.13474/v1

License: (c) (i) This work is licensed under a Creative Commons Attribution 4.0 International License.

Read Full License 


\section{Abstract}

Background To evaluate the number of patients with early-stage breast cancer, undergoing axillary lymph node dissection for metastatic sentinel lymph nodes, who could benefit from the omission of axillary surgery following the application of ACOSOG Z0011 trial criteria.Methods A retrospective cohort study conducted in the Women's Hospital of the State University of Campinas. The study population included 384 women diagnosed with early-stage invasive breast cancer, clinically negative axilla, treated with breast-conserving surgery and sentinel lymph node biopsy, radiation therapy, chemotherapy and/or endocrine therapy, from January 2005 to December 2010. ACOSOG Z0011 trial criteria were applied to this population and statistical analysis was carried out to make a comparison between populations.Results A total of 384 patients underwent breast-conserving surgery and sentinel lymph node biopsy. Of the total number of patients, 86 women underwent axillary lymph node dissection for metastatic sentinel lymph nodes. One patient underwent axillary node dissection due to a suspicious SLN intra-operatively. Among these patients, 82/87 (94.3\%) had one to two involved sentinel lymph nodes and met criteria for the ACOSOG Z0011 trial with the omission of axillary lymph node dissection. Among the 82 eligible women, there were only 13 cases $(15.9 \%)$ of lymphovascular invasion and 62 cases $(75.6 \%)$ of tumors measuring up to $2 \mathrm{~cm}$ in diameter (T1).Conclusions When eligibility for ACOSOG Z0011 trial criteria was retrospectively exported to our study population, $94.3 \%$ of the patients with one to two positive sentinel lymph nodes would benefit from the omission of axillary lymph node dissection. The high rate in our study may be explained by the large number of patients with tumors up to $2.0 \mathrm{~cm}$ in size and the small rate of lymphovascular invasion, which are indicative of a favorable prognosis.

\section{Background}

Recommendations for axillary management in breast cancer have changed rapidly over the years with advances in surgical techniques and scientific knowledge.

Sentinel lymph node biopsy (SLNB) in breast cancer with clinically negative axilla has currently been included in staging protocols in the majority of referral centers for breast cancer treatment. Axillary lymph node dissection (ALND) still has a major role in locoregional disease control. Furthermore, in case of positive sentinel lymph nodes (SLNs) it was the standard of practice ${ }^{(1,2,3,4,5,6)}$, a fact that has been modified with new studies.

Various studies have attempted to determine factors associated with a higher chance of additional lymph node involvement in the remaining axilla after a positive SLNB. The intent is to help decide which patients should undergo ALND, thus avoiding more invasive surgeries in patients who would fail to derive any benefit $(7)$.

Nevertheless, recent research has shown that ALND can be avoided in many cases, even in patients with positive SLN. In these cases, surgery could be equally replaced by radiotherapy directly or tangentially to 
the axillary drainage chain, reducing further morbiditiy and sequelae of surgical treatment, without affecting patient prognosis $(8,9,10)$.

The ACOSOG Z0011 Trial evaluated women with invasive breast carcinoma, who had tumors measuring up to $5 \mathrm{~cm}$ (T1 and T2), clinically negative axilla and undergoing breast-conserving surgery (BCS) or mastectomy. All patients received proper radiotherapy and systemic adjuvant therapy. Women who had up to 2 metastatic axillary lymph nodes at the time of SLNB were randomized to ALND or received no complementary axillary therapy. The study showed that there was no difference in overall survival and disease-free survival between groups ${ }^{(8)}$.

The aim of the AMAROS trial was to compare ALND versus axillary radiotherapy. It evaluated women with invasive breast carcinoma, tumors measuring up to $5 \mathrm{~cm}$ ( $\mathrm{T} 1$ and $\mathrm{T} 2$ ), clinically negative axilla, undergoing BCS or mastectomy. Those with positive SLN were randomly assigned to ALND or axillary radiotherapy. Both groups achieved good tumor control at the 5-year follow-up. However, the group undergoing radiotherapy to the axilla had less morbiditiy, mainly resulting from lymphedema ${ }^{(9)}$.

Some centers have already adopted a conservative approach to the axilla based mainly on ACOSOG Z0011 and AMAROS trials.

The aim of the current study was to apply ACOSOG Z0011 trial criteria to women undergoing breast cancer treatment in the Prof. Dr. José Aristodemo Pinotti Women's Hospital - CAISM and investigate the number of women who were spared from ALND.

\section{Methods}

The current study is part of a retrospective cohort study that was approved by the Research Ethics Committee of the University of Campinas School of Medicine, CAAE 36001314.4.0000.5404, under ${ }^{\circ}$ 839.129 .

Data collection was conducted using medical records of invasive breast cancer patients managed in the Prof. Dr. José Aristodemo Pinotti Women's Hospital - CAISM from February 2005 to December 2010. A total of 501 patients with $\mathrm{T} 1$ and $\mathrm{T} 2$ breast cancer and clinically negative axilla and without neoadjuvant treatment, underwent mastectomy or BCS always followed by SLNB. Of the total number, 399 were selected for BCS with SLNB. The SLN was identified by injection of radioactive technetium colloid and subsequent lymphoscintigraphy of the breast or by injection of patent blue dye in an isolated or combined technique. SLN were evaluated in frozen tissue section examination by touch imprint cytology. When positive, diagnosis was further confirmed by histologic frozen section examination. When negative, the surgeon awaited the results of paraffin tissue section and if positive, surgery would proceed with total ALND. Immunohistochemistry was performed if the paraffin tissue section was free of cancer. Women who had lymph node involvement in the paraffin tissue section such as macrometastases or micrometastases later underwent ALND, except for the detection of micrometastases or isolated tumor cells (ITC) on immunohistochemistry. All women had clear surgical margins in the first surgery or in 
further surgeries to widen the incision and later receive adjuvant treatment according to institutional protocol and radiotherapy to the remaining breast with a radiation boost to the surgical scar. The ipsilateral supraclavicular fossa was part of the irradiation field in case of positivity due to macrometastases of axillary lymph nodes in any number.

\section{Statistical analysis}

To describe sample profile according to variables studied, Tables of frequencies of categorical variables and descriptive statistics of numerical variables were constructed. To compare categorical variables between groups, the chi-square or Fisher's exact test were used. To compare numerical variables, the Mann-Whitney test was used. The level of significance adopted for the statistical tests was $5 \%$, i.e., $p<0.05$. The software package used was SAS, version 9.2.

\section{Results}

Among 501 selected patients, 101 underwent mastectomy and 384 received BCS. SLN was identified in 486 cases. Of the patients undergoing BCS, 295 were SLN-negative and 86 were SLN-positive. ALND was conducted in 87 patients [ 86 with SLN involvement and one with a macroscopically suspicious node during surgery (Figure 1)]. Concerning the number of involved SLNs, 82/86 (95.3\%) of the women had one or two positive SLNs (study population), 1 had 3 involved SLNs (1.2\%) and 1 had 4 (1.2\%) or more involved SLNs (Table 1).

Clinical and pathological characteristics are described in Table 2. The majority of the patient population was over 50 years of age, with a mean of 56 years in the total population and 55 years in the study population. Most tumors were invasive carcinomas of no special type (invasive ductal carcinoma), that measured up to $1 \mathrm{~cm}$ in diameter, expressed estrogen and/or progesterone receptors, did not overexpress HER2 and had no lymphovascular invasion.

Table 3 compares the study population with patients who had been spared from axillary surgery in the ACOSOG Z0011 trial (up to 2 positive SLNs). There was no difference in patient age between both groups. No difference was observed in tumor type and expression of hormone receptors and HER2. Nevertheless, in our population there was a higher number of patients with tumors measuring up to $2 \mathrm{~cm}$ $(p=0.039)$ and fewer cases of lymphovascular invasion $(p<0.001)$, presenting a larger case study of tumors with a more favorable prognosis.

\section{Discussion}

The aim of this study was to reproduce the ACOSOG Z0011 trial criteria in 384 women with early-stage T1 - T2 invasive breast cancer with clinically negative axilla, undergoing BCS and SLNB. Of the total number of women, 87(22.6\%) underwent ALND and 297 (77.3\%) were spared from further treatment. If we had applied the ACOSOG Z0011 trial criteria, 82/87 (94.3\%) more women might have benefitted from 
the omission of ALND, corresponding to 379 women spared from axillary surgery, i.e., $98.7 \%$ of all women undergoing SLNB.

In 2016, Verheuvel et al. investigated 916 cases undergoing ALND for SLN involvement or positive axillary lymph node diagnosed by ultrasound-guided biopsy. Of the total number of patients, 558 (61\%) could have benefitted from the omission of ALND. Those authors considered micrometastases and ITC as NO. In 2013, Delpech et al applied the same criteria to 125 SLN-positive patients undergoing ALND. Among those women, 87 (69.7\%) were potentially eligible for omission of ALND ${ }^{(11)}$. In our study, we found an even higher number of cases in which ALND could have been avoided.

The pre-established concept of ALND in all patients with SLN involvement has currently undergone modifications. When the SLN technique emerged in the late nineties, it was a major advance in women with negative axilla who would no longer require ALND. Nevertheless, SLN-positive patients still received axillary dissection. ALND may cause complications such as postoperative seroma, infection, sensory disturbances in the ispilateral arm in the medium and long-term, in addition to lymphedema in up to $40 \%$ of cases at the 10-year follow-up ${ }^{(12)}$. Complications after ALND interfere negatively in the quality of life of these women, increasing treatment expenses ${ }^{(13)}$.

In 2014, Sackey et al. compared a group of women undergoing SLNB alone to another group undergoing ALND due to positive SLN and found a significantly lower risk of lymphedema in women who had not received ALND. In 2013, in a long-term follow-up study, De Gournay et al. failed to find any case of lymphedema in the SLNB group, while lymphedema rates were $10.3 \%$ in the ALND group and $7 \%$ in the SLNB group followed by $\operatorname{ALND}^{(14,15)}$. It can be inferred that the omission of ALND in a public health care facility of a developing country such as ours, could reduce the cost of surgical treatment and management of potential sequelae related to ALND. Furthermore, it could promote a better quality of life in a large number of women by reducing the possibility of lymphedema.

Lymph node involvement in the remaining axilla ranges from $20 \%$ to $40 \%$ in SLN-positive patients $(1,2,3)$. In the recent past, studies have attempted to correlate predictive factors for lymph node involvement in the remaining axilla. Memorial Sloan-Kettering Cancer Center - MSCC created a nomogram using factors correlated with the tumor: size, histologic type, nuclear grade, lymphovascular invasion, multifocality and estrogen receptor, thus screening a group of SLN-positive women who might benefit from the omission of $\mathrm{ALND}^{(3)}$. A number of attempts have been made to reproduce and validate the MSCC nomogram, with conflicting results $(16,17)$.

Currently, both locoregional and distant disease control have improved by systemic therapy, allowing for less extensive axillary surgery. Studies have demonstrated that even with the potential persistence of disease in the remaining axilla, regional recurrence rates have not corresponded to these possibilities ${ }^{(10)}$. 
Radiation therapy after BCS using tangential fields to the axilla in the ACOSOG Z0011 trial probably covers the remaining positive axillary nodes ${ }^{(18)}$. The AMAROS trial also showed that radiation therapy had promising results in local and systemic disease control, as well as in comorbidities, lymphedema in particular ${ }^{(9)}$. Thus, regional axillary treatment with surgery or even radiation therapy omitted in some select cases, may confer benefits in quality of life and reduce treatment costs.

The novelty of the ACOSOG Z0011 trial lies in the demonstration of good outcomes without any further treatment of the remaining axilla in women with up to 2 involved $\operatorname{SLN}{ }^{(18)}$.

The current study has some limitations. This is a retrospective study and initially in our center it was routine practice to consider the presence of micrometastases and ITC as a positive axilla. Over time, there was a change in concept and this practice was abandoned. Therefore, a possible explanation for such a high number of ALND that could have been avoided is the number of patients with micrometastases and ITC. Currently considered N0, these patients were entered in the case study of N1, and underwent ALND at the time.

In addition to reproducing ACOSOG Z0011 trial criteria ${ }^{(19)}$, this study showed a paradigm shift in axillary treatment over the years. It enabled us to make a critical evaluation of our routine practice, which is no different from other referral centers worldwide ${ }^{(11,19)}$. Self-criticism is fundamental for program implementation to provide patients with the best treatment, along with the least associated comorbidities and lowest cost possible, since this is a public health care facility in a developing country.

\section{Conclusions}

ACOSOG Z0011 trial criteria can be applied to a select group of SLN-positive patients, reducing the costs and morbidities of breast cancer surgery.

\section{Abbreviations}

SLNB: Sentinel lymph node biopsy

ALND: Axillary lymph node dissection

SLN: sentinel lymph nodes

BCS: breast-conserving surgery

ITC: isolated tumor cells

\section{Declarations}

\section{Ethics approval and consent to participate}


This study was approved by the Ethics Committee of the State University of Campinas School of Medicine, CAAE 36001314.4.0000.5404, under number 839.129. The Committee waived the need for consente because data were obtained from medical archives of the Prof. Dr. José Aristodemo Pinotti Women's Hospital - CAISM, without harm to treatment of the women.

\section{Consent for publication}

Not applicable.

\section{Availability of data and materials}

Data are available at Prof. Dr. José Aristodemo Pinotti Women's Hospital - CAISM medical archive.

\section{Competing interests}

The authors have no conflict of interest to declare.

\section{Funding}

This study was carried out on its own resources without external funding.

\section{Authors' contributions}

JYS and KPS contributed to surgery, conception and design, acquisition, analysis and interpretation of data, drafting the manuscript. CC was involved in surgery and drafting the manuscript. CCF was involved in surgery and acquisition of data. CE was involved in acquisition of data. LCZ revising the manuscript critically for important intellectual content. All authors approved the final version to be published and agreed to be accountable for all aspects of the work in ensuring that questions related to the accuracy or integrity of any part of the work were appropriately investigated and resolved.

\section{Acknowledgments}

The authors thank to Fernando Tocchet, Gabriel Yaemon Ikejiri, Patricia Kajikawa, Tamara Pinto de Oliveira Araújo and to Elymar da Costa Machado. 
Author details

${ }^{1}$ Universidade Estadual de Campinas - UNICAMP (State University of Campinas School of Medicine), Obstetrics and Gynecology Department, Alexander Flemming St, 101, Campinas, São Paulo, Brazil. Zip code 13083-790.

${ }^{2}$ Faculdade São Leopoldo Mandic (São Leopoldo Mandic Medical School), Obstetrics and Gynecology Department, José Rocha Junqueira St, 13, Campinas, São Paulo, Brazil. Zip code 13045-755

\section{References}

1. Veronesi U, Paganelli G, Viale G, Galimberti V, Luini A, Zurrida S, et al. Sentinel lymph node biopsy and axillary dissection in breast cancer. results in a large series. J Natl Cancer Inst. 1999;91(4):36873.

2. Veronesi U, Paganelli G, Viale G, Luini A, Zurrida S, Galimberti V et al. A randomized comparison of sentinel-node biopsy with routine axillary dissection in breast cancer. N Eng/ J 2003;349(6):546-53.

3. Mansel RE, Fallowfield L, Kissin M, Goyal A, Newcombe RG, Dixon JM et al. Randomized multicenter trial of sentinel node biopsy versus standard axillary treatment in operable breast cancer: the ALMANAC Trial. J Natl Cancer Inst. 2006;98(9):599-609.

4. Veronesi U, Viale G, Paganelli G, Zurrida S, Luini A, Galimberti V et al. Sentinel Lymph Node Biopsy in Breast Cancer Ten-Year Results of a Randomized Controlled Study. Ann Surg. 2010;251(4):595-600.

5. Krag DN, Anderson SJ, Julian TB, Brown AM, Harlow SP, Costantino JP et al. Sentinel-lymph-node resection compared with conventional axillary-lymph-node dissection in clinically node-negative patients with breast cancer: overall survival findings from the NSABP B-32 randomised phase 3 trial. Lancet Oncol. 2010;11(10):927-33.

6. de Boniface J, Frisell J, Bergkvist L, Andersson Y, Swedish Breast CancerGroup and the Swedish Society of Breast et al, on behalf of the Swedish Breast Cancer Group and the Swedish Society of Breast Surgery. Ten-year report on axillary recurrence after negative sentinel node biopsy for breast cancer from the Swedish Multicentre Cohort Study. Br J Surg. 2017;104(3):238-47.

7. Van Zee KJ, Manasseh DM, Bevilacqua JL, Boolbol SK, Fey JV, Tan LK, Borgen PI et al. A nomogram for predicting the likelihood of additional nodal metastases in breast cancer patients with a positive sentinel node b Ann Sur Oncol. 2003;10(10):1140-51.

8. Giuliano AE, McCall L, Beitsch P, Whitworth PW, Blumencranz P, Leitch AM et al. Locoregional recurrence after sentinel lymph node dissection with or without axillary dissection in patients with sentinel lymph node metastases the American College of Surgeons Oncology Group Z0011 randomized trial. Ann Surg. 2010;252:426-32. 
9. Donker M, van Tienhoven G, Straver ME, Meijnen P, van de Velde CJ, Mansel RE, et al. Radiotherapy or surgery of the axilla after a positive sentinel node in breast cancer (EORTC 10981-22023 AMAROS): a randomised, multicentre, open-label, phase 3 non-inferiority trial. Lancet Oncol. 2014;15(12):1303-10.

10. Morrow M, Van Zee KJ, Patil S, Petruolo O, Mamtani A, Barrio AV et al. Axillary dissection and nodal irradiation can be avoided for most node-positive Z0011-eligible breast cancers: a prospective validation study of 793 patients. Ann Surg. 2017;266(3):457-62.

11. Verheuvel NC, Voogd AC, Tjan-Heijnen VCG, Roumen RMH. Potential impact of Z0011 derived criteria to omit axillary lymph node dissection in node positive breast cancer patients. Eur J Surg Oncol. 2016;42(8):1162-68.

12. Ribeiro Pereira ACP, Koifman RJ, Bergmann A. Incidenceand risk factors of lymphedema after breast cancer treatment: 10 years of follow-up. 2017;36:67-73.

13. Fleissig A, Fallowfield LJ, Langridge Cl, Johnson L, Newcombe RG, Dixon JM, Kissin M et al. Postoperative arm morbidity and quality of life: results of the ALMANAC randomised trial comparing sentinel node biopsy with standard axillary treatment in the management of patients with early breast cancer. Breast Cancer Res Treat 2006, 95(3): 279-293.

14. Sackey H, Magnuson A, Sandelin K, Liljegren G, Bergkvist L, Fulep ZF, et al. Arm lymphoedema after axillary surgery in women with invasive breast cancer. 2014;101:390-97.

15. De Gournay E, A Guyomard, C Coutant, S Boulet, P Arveux, S Causeret, et al. Impact of sentinel node biopsy on long-term quality of life in breast cancer patients. Br J Cancer. 2013;109:2783-91.

16. Pugliese MS, Karam AK, Hsu M, Stempel MM, Patil SM, Ho AY et al. Predictors of completion axillary lymph node dissection in patients with immunohistochemical metastases to the sentinel lymph node in breast Ann Surg Oncol. 2010;17:1063-68.

17. Vieni S, Graceffa G, La Mendola R, Latteri S, Cordova A, Latteri MA et al. Application of a predictive model of axillary lymph node status in patients with sentinel node metastasis from breast cancer. A retrospective cohort study. Int J Surg. 2016;35:58-63.

18. Giuliano AE, Ballman K, MacCall L, Whitworth PW, Blumencranz $P$ et al. Locoregional recurrence after sentinel lymph node dissection with or without axillary dissection in patients with sentinel lymph node metastases. Long-term follow-up from the American College of Surgeons Oncology Group (Alliance) ACOSOG Z0011 Randomized Trial. Ann Surg. 2016;264(3):413-20.

19. Delpech Y, Bricou A, Lousquy R, Hudry D, Jankowski C, Willecocq C, et al. The Exportability of the ACOSOG Z0011 criteria for omitting axillary lymph node dissection after positive sentinel lymph node biopsy findings: A multicenter study. Ann Surg Oncol. 2013;20:2556-61.

\section{Tables}




\section{Table 1. Number of involved lymph nodes}

\begin{tabular}{ccc}
\hline Number of positive SN & $\mathrm{N}=86$ & Percent(\%) \\
\hline 1 & 70 & 81,4 \\
2 & 12 & 13,9 \\
3 & 1 & 1,2 \\
$>=4$ & 1 & 1,2 \\
Missing & 2 & 2,3 \\
\hline
\end{tabular}

Table 2. Clinicopathological features of the treated patients

\begin{tabular}{|c|c|c|c|c|}
\hline Characteristics & Total sample $(\mathrm{N}=384)$ & Studied population $(\mathrm{N}=82)$ & Complementary $(\mathrm{N}=302)$ & $\mathrm{p}$ value \\
\hline \multicolumn{5}{|l|}{ Age (yr) } \\
\hline Median (min, max) & $56(28,83)$ & $55(31,82)$ & $56(28,83)$ & 0.363 \\
\hline Missing & 0 & 0 & 0 & \\
\hline \multicolumn{5}{|l|}{ Age (yr) } \\
\hline$<=50, N(\%)$ & $120(31.3)$ & $29(35.4)$ & $91(30.1)$ & 0.365 \\
\hline$>50, N(\%)$ & $264(68.7)$ & $53(64.6)$ & $211(69.9)$ & \\
\hline Missing & 0 & 0 & 0 & \\
\hline \multicolumn{5}{|l|}{ Clinical T stage, $\mathrm{N}(\%)$} \\
\hline $\mathrm{T} 1$ & $300(78.1)$ & $62(75.6)$ & $238(78.8)$ & 0.715 \\
\hline $\mathrm{T} 2$ & 75 (19.5) & $19(23.2)$ & $56(18.5)$ & \\
\hline T3 & $6(1.6)$ & $1(1.2)$ & $5(1.6)$ & \\
\hline Missing & $3(0.8)$ & 0 & $3(1.1)$ & \\
\hline \multicolumn{5}{|c|}{ Receptor Status, N(\%) } \\
\hline $\mathrm{ER}+$ and/or PgR+ & $318(82.8)$ & 75 (91.5) & $243(82.1)$ & 0.040 \\
\hline $\mathrm{ER}-/ \mathrm{PgR}-$ & $60(15.6)$ & $7(8.5)$ & $53(17.9)$ & \\
\hline Missing & $6(1.6)$ & 0 & 6 & \\
\hline \multicolumn{5}{|l|}{ HER2,N(\%) } \\
\hline HER2 + & $59(15.4)$ & $10(12.2)$ & $49(16.2)$ & 0.408 \\
\hline HER2 - & $182(47.4)$ & $40(48.8)$ & $142(47)$ & \\
\hline Missing & $143(37.2)$ & $32(39)$ & $111(36.8)$ & \\
\hline \multicolumn{5}{|l|}{ LVI, N(\%) } \\
\hline Yes & $34(8,8)$ & 13 (15.9) & $21(6.9)$ & 0.012 \\
\hline No & 349 (90.9) & $69(84.2)$ & $280(92.7)$ & \\
\hline Missing & $1(0,3)$ & 0 & $1(0.4)$ & \\
\hline \multicolumn{5}{|l|}{ Tumor type, N(\%) } \\
\hline Infiltrating ductal & $317(82,5)$ & $66(80.5)$ & $251(83.1)$ & 0.314 \\
\hline Infiltrating lobular & $13(3.4)$ & $5(6.1)$ & $8(2.6)$ & \\
\hline Other & $48(12.5)$ & $10(12.2)$ & $38(12.6)$ & \\
\hline Missing & $6(1.6)$ & $1(1.2)$ & $5(1.7)$ & \\
\hline
\end{tabular}


Table 3 - Clinicopathological features of the studied population versus ACOSOG Z0011

\begin{tabular}{|c|c|c|c|}
\hline Characteristics & Studied population $(\mathrm{N}=82)$ & Z001 Trial $(\mathrm{N}=420)$ & $\mathrm{p}$ value \\
\hline \multicolumn{4}{|l|}{ Age (yr) } \\
\hline Median (min, max) & $55(31,82)$ & $56(24,92)$ & 0.567 \\
\hline Missing & 0 & 7 & \\
\hline \multicolumn{4}{|l|}{ Age (yr) } \\
\hline$<=50, N(\%)$ & $29(35.4)$ & $135(32.1)$ & 0.638 \\
\hline$>50, \mathrm{~N}(\%)$ & $53(64.6)$ & $278(66.2)$ & \\
\hline Missing & 0 & $7(1.7)$ & \\
\hline \multicolumn{4}{|l|}{ Clinical T stage, N(\%) } \\
\hline $\mathrm{T} 1$ & $62(75.6)$ & $284(67.6)$ & 0.039 \\
\hline $\mathrm{T} 2$ & $19(23.2)$ & 134 (31.9) & \\
\hline T3 & $1(1.2)$ & 0 & \\
\hline Missing & 0 & $2(0.5)$ & \\
\hline \multicolumn{4}{|c|}{ Receptor Status, N(\%) } \\
\hline $\mathrm{ER}+$ and/or PgR+ & $75(91.5)$ & $320(76.2)$ & 0.069 \\
\hline ER-/PgR- & $7(8.5)$ & $63(15)$ & \\
\hline Missing & 0 & $37(8.8)$ & \\
\hline \multicolumn{4}{|l|}{ LVI, N(\%) } \\
\hline Yes & $13(15.9)$ & $129(30.7)$ & $<0.001$ \\
\hline No & $69(84.2)$ & $189(45)$ & \\
\hline Missing & 0 & $102(24.3)$ & \\
\hline \multicolumn{4}{|l|}{ Tumor type, N(\%) } \\
\hline Infiltrating ductal & $66(80.5)$ & 344 (81.9) & 0.921 \\
\hline Infiltrating lobular & $5(6.1)$ & $27(6.4)$ & \\
\hline Other & $10(12.2)$ & $45(10.7)$ & \\
\hline Missing & $1(1.2)$ & $4(1)$ & \\
\hline
\end{tabular}

Figures 
Invasive breast cancer T1,2N0

$\mathrm{N}=501$

Mastectomy or Breast Conservative Surgery (BCS)

with Sentinel Node Biopsy (SNB)

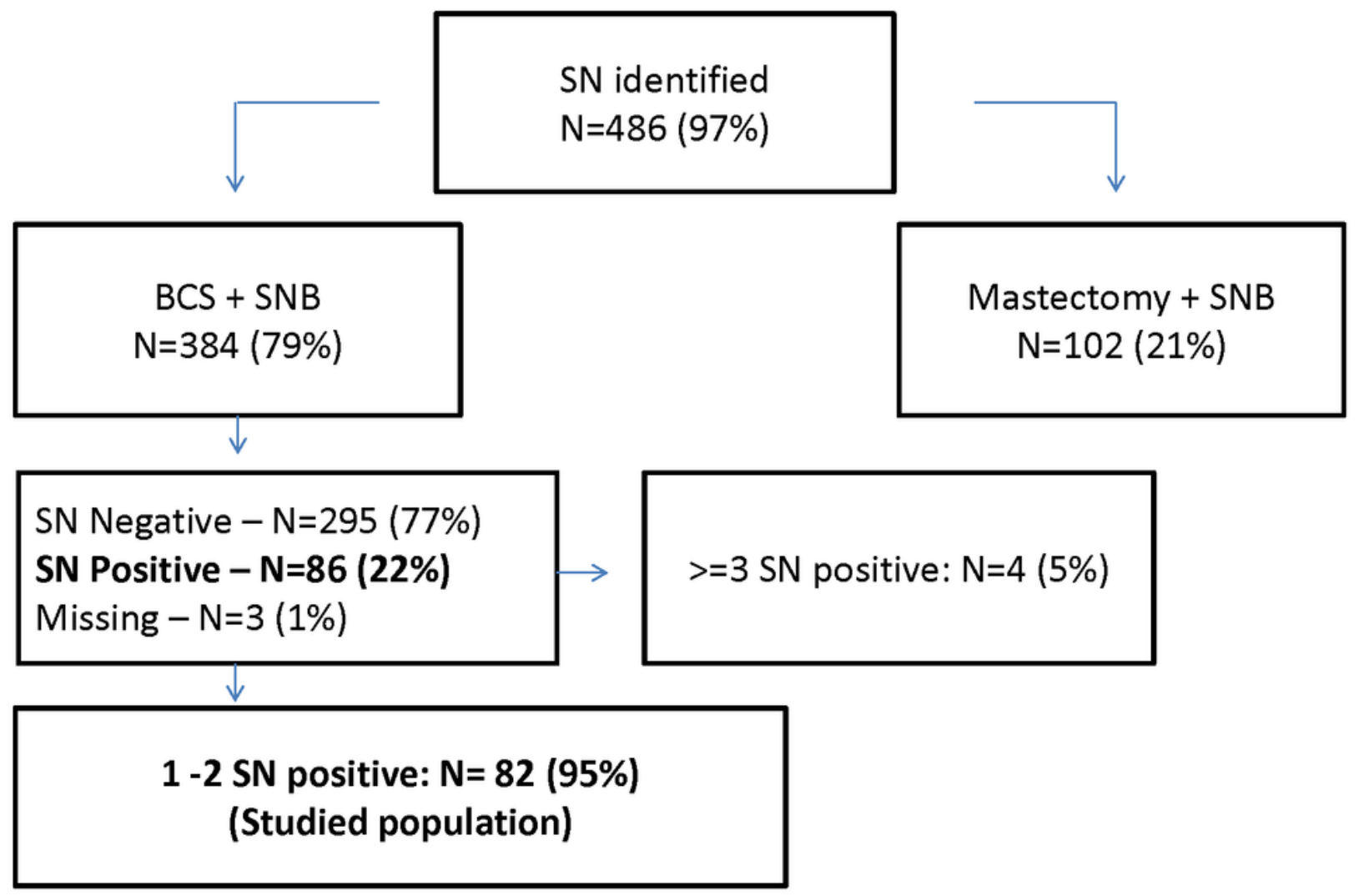

Figure 1 